
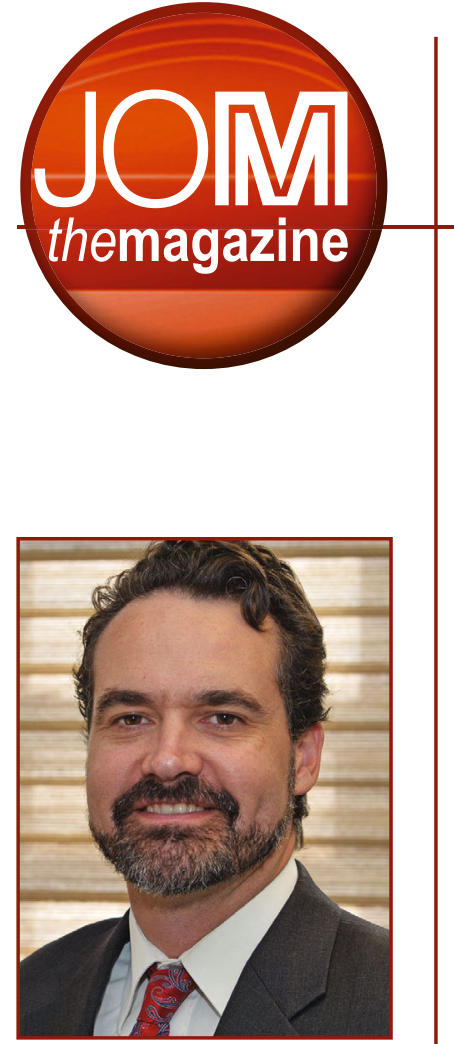

Eric N. Brown

"The new services

that Springer

brings...will result

in an even better

end product for our

authors."

-Eric N. Brown,

TMS Board of

Directors

\title{
TMS and Springer Partner on Proceedings Publications
}

\section{Lynne Robinson}

\section{TMS content update}

Look for news and updates on TMS publications and online resources, as well as opportunities for editors and authors, in this regular JOM feature.
Enhanced discoverability, an improved publishing experience, and a more polished final product are just a few of the benefits that TMS will be offering to proceedings authors through its new publishing partnership with Springer Science+Business Media.

Springer will begin releasing TMS products on October 1, 2016, to include proceedings publications, as well as original monographs and textbooks. It will also carry a selection of more than 50 best-selling and recent TMS backlist titles. TMS products that are still in print, but not available through Springer, can be purchased through John Wiley \& Sons, TMS's current publishing partner.

Eric N. Brown, Content, Development \& Dissemination Director of the TMS
Board of Directors, noted that the main impetus for moving to Springer was to preserve the aspects of TMS publishing that members indicated were of high value, while also leveraging the considerable author resources that Springer could offer. "In the changing publishing world, Springer is engaging with us to provide TMS members with the benefits that the Board has heard are important to them," he said. "This includes publishing at-meeting proceedings in a hard-copy format. The new services that Springer brings, such as copyediting and consistent formatting of proceedings papers, will result in an even better end product for our authors."

Beyond this improved production process, Brown noted that Springer's reputation and reach will open substantial

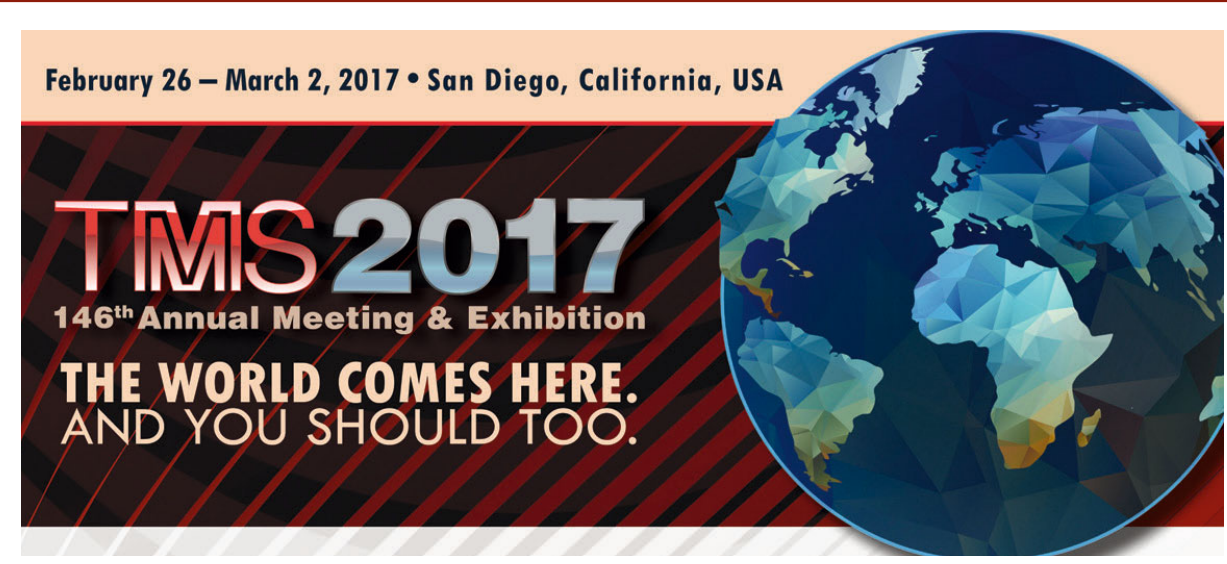

\section{TMS2017 Proceedings Update}

Authors invited to submit proceedings papers for the TMS 2017 Annual Meeting \& Exhibition (TMS2017) will be among the first to enjoy the benefits of the new publishing partnership between TMS and Springer. The publishing experience will be different than in previous years, with new manuscript preparation instructions. Proceedings publications will no longer include camera-ready copy supplied by authors; papers will be formatted consistently during the production process. Authors will be able to review their formatted work prior to publication through an e-proofing system.

The TMS 2017 Annual Meeting \& Exhibition will take place February 26-March 2, 2017 in San Diego, California. The deadline for manuscripts is September 1, 2016. 


\section{焦 Springer Springer Discount for TMS Members}

Under TMS's new publishing agreement with Springer, TMS members will receive a $20 \%$ discount on all books, both print and electronic, in the Springer catalog. Details on how to access this benefit will be shared with TMS members prior to October 1, 2016. opportunities to TMS authors for exposure. Like TMS journals, TMS publications content will now be accessible on SpringerLink (www.springerlink.com), one of the world's leading internet science portals. "TMS has been publishing its journals with Springer for nearly 10 years, with significant gains in their performance indicators throughout that time," said Brown. "Springer merged with Nature Publishing last year to form Springer Nature, providing an even wider publishing network."

What will not change from the past publishing process is assignment of digital object identifier (DOI) numbers to single articles and international distribution of whole volumes. Springer will also continue to submit all TMS publications to major abstracting and indexing services to assist authors with measuring the impact of their work. A new, related benefit offered by Springer will be access to a Bookmetrix tool (www.bookmetrix.com) that will enable authors to compile the number of citations and downloads in one place for each of their individual articles and books.

James J. Robinson, TMS executive director, is confident that Springer's proven track record as a publishing partner with TMS journals bodes well for the future of other TMS publications. "Over the last decade, the TMS partnership with Springer has been remarkably successful, helping TMS volunteers and staff grow the reach, impact, and scope of our family of periodicals," he said. "I have every expectation that expanding our relationship with Springer will have equally impactful outcomes for our proceedings and books."
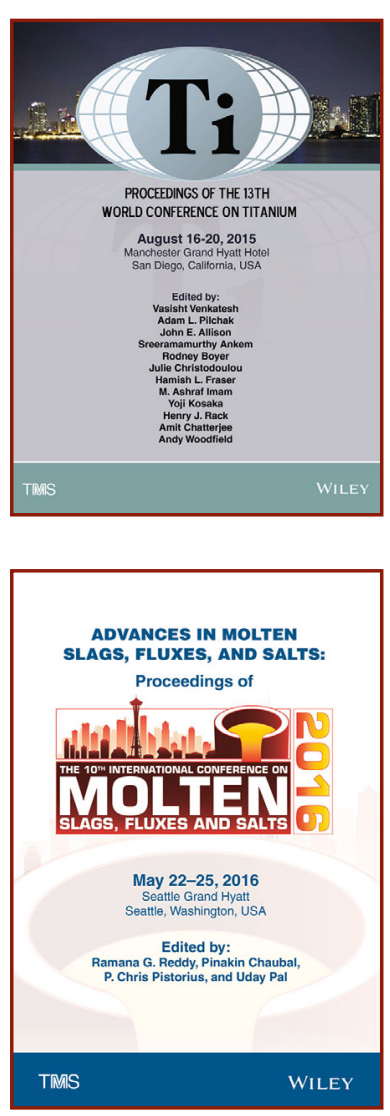

\section{New Titles Released}

TMS is pleased to announce the release of the following titles with its current publishing partner, John Wiley \& Sons at www.wiley.com. Until September 30, 2016, TMS members receive a 35 percent discount on these publications, as well as all other products sold by Wiley. Access the TMS member discount code in the TMS-Wiley Bookstore section of the TMS Knowledge Resource Center at knowledge.tms.org.

\section{Proceedings of the 13th} World Conference on Titanium Editors: Vasisht Venkatesh, Adam L. Pilchak, John E. Allison, Sreeramamurthy Ankem, Rodney Boyer, Julie Christodoulou, Hamish L. Fraser, M. Ashraf Imam, Yoji Kosaka, Henry J. Rack, Amit Chatterjee, and Andy Woodfield

The papers contained in this volume highlight recent advances and new opportunities for titanium alloys, as presented by leading experts in the field. Contributions are organized within the following topic areas: Additive and Near Net Shape Manufacturing; Aerospace Applications; Composition- MicrostructureProperties; Biomedical Applications; Environmental Behavior; Extraction and Powder Production; Integrated
Computational Materials Engineering; Intermetallics and Metal Matrix Composites; Melting and Casting; and Wrought Processing.

\section{Advances in Molten Slags, Fluxes, and Salts: \\ Proceedings of the 10th International Conference on Molten Slags, Fluxes and Salts (Molten16) \\ Editors: Ramana G. Reddy, Pinakin Chaubal, P. Chris Pistorius, Uday Pal}

Molten16 focused on aspects of ferrous and non-ferrous metallurgy in which ionic melts, slags, fluxes or salts play important roles in industrial and economic growth. The Molten16 proceedings volume compiles papers presented on a range of technical topics, including: thermodynamic properties and phase diagrams and kinetics of slags, fluxes, and salts; physical properties of slags, fluxes, and salts; structural studies of slags; interfacial and process phenomena involving foaming, bubble formation, and drainage; slag recycling, refractory erosion/ corrosion, and freeze linings; and recycling and utilization of metallurgical slags and models and their applications in process improvement and optimization. 